Supporting Information for

\title{
Chemical Etching of Screw Dislocated Transition Metal Dichalcogenides
}

\author{
Yuzhou Zhao, ${ }^{1, \#}$ Xiao Kong, ${ }^{2,}$ \# Melinda J. Shearer, ${ }^{1}$ Feng Ding ${ }^{2,3, *}$ and Song $\operatorname{Jin}^{1, *}$ \\ ${ }^{1}$ Department of Chemistry, University of Wisconsin-Madison, 1101 University Avenue, \\ Madison, Wisconsin 53706, United States \\ ${ }^{2}$ Centre for Multidimensional Carbon Materials, Institute for Basic Science, Ulsan 44919, Korea \\ ${ }^{3}$ School of Materials Science and Engineering, Ulsan National Institute of Science and \\ Technology, Ulsan 44919, Korea \\ "Contributed equally \\ *Corresponding authors. E-mail: jin@chem.wisc.edu,f.ding@unist.ac.kr
}

\section{Methods}

Synthesis of screw dislocated WSe 2 nanoplates. Screw dislocated $\mathrm{WSe}_{2}$ nanoplates were grown on (100) silicon substrates via a chemical vapor deposition (CVD) process using $\mathrm{WO}_{3}$ and $\mathrm{Se}$ as the precursors, following our previous work. ${ }^{1} \mathrm{WO}_{3}$ powder (approximately $300 \mathrm{mg}$, Sigma Aldrich) was placed in an alumina boat in a fused silica tube (outer diameter 1 inch) placed in the center of a Lindberg Blue M tube furnace, and the silicon substrates (UniversityWafer, Inc.) were placed facing down on top of the boat. Another boat filled with Se powder (approximately 600 mg, Sigma Aldrich) was placed upstream outside the heating zone of the tube furnace. The CVD system was preheated at $200{ }^{\circ} \mathrm{C}$ for 10 min under an argon flow rate of $120 \mathrm{sccm}$ to drive off the moisture in the system. The tube was then heated to $880{ }^{\circ} \mathrm{C}$ under a pressure of 780 torr with an argon flow of $50 \mathrm{sccm}$. Once the reaction temperature was reached, the Se boat was pushed into the heating zone using a magnet so that the front of the boat was at $600{ }^{\circ} \mathrm{C}$. Simultaneously, $\mathrm{H}_{2}$ gas was turned on at a flow rate of $2 \mathrm{sccm}$. At 2 and $4 \mathrm{~min}$, the Se boat was pushed slightly further 
into the tube furnace, and finally at $5 \mathrm{~min}$, the Se boat was pushed completely inside the furnace. The reaction went on for 7-10 min before the furnace was opened and cooled down rapidly.

Synthesis of screw dislocated $W_{2}$ nanoplates. Based on our previous work, ${ }^{2}$ screw-dislocated $\mathrm{WS}_{2}$ nanoplates were grown on $300 \mathrm{~nm} \mathrm{SiO}_{2} / \mathrm{Si}$ substrates via a water vapor-assisted chemical vapor transport process using $\mathrm{WS}_{2}$ precursor and $\mathrm{CaSO}_{4} \cdot 2 \mathrm{H}_{2} \mathrm{O}$ as the water vapor source. $\mathrm{WS}_{2}$ powder (approximately $100 \mathrm{mg}$, Alfa Aesar) was placed in a fused silica boat in the center of the first zone in a three-zone tube furnace, and the $\mathrm{SiO}_{2} / \mathrm{Si}$ substrate was placed between the second and the third zone facing up. An alumina boat filled with $\mathrm{CaSO}_{4} \cdot 2 \mathrm{H}_{2} \mathrm{O}$ powder (approximately 1 g, Sigma Aldrich) was placed upstream from the furnace, where heating tapes controlled the temperature. $100 \mathrm{sccm}$ argon was used as the carrier gas, and the pressure was maintained at 800 torr to minimize the penetration of ambient moisture into the reactor. The second zone was heated to $1200{ }^{\circ} \mathrm{C}$ at a rate of $20{ }^{\circ} \mathrm{C} / \mathrm{min}$, and simultaneously the third zone was heated to $900{ }^{\circ} \mathrm{C}$ at the same rate without heating $\mathrm{CaSO}_{4} \cdot 2 \mathrm{H}_{2} \mathrm{O}$. Once reaching the temperature, the $\mathrm{CaSO}_{4} \cdot 2 \mathrm{H}_{2} \mathrm{O}$ was heated to $120{ }^{\circ} \mathrm{C}$ under an argon flow of $100 \mathrm{sccm}$ to release the water vapor, and the $\mathrm{WS}_{2}$ precursor boat was pushed into the second zone by a magnet coupled positioner and a quartz rod to initiate the reaction. After 15 min reaction, the furnace was opened and cooled down rapidly.

$\mathrm{H}_{2} \mathrm{O}_{2}$ solution etching of dislocated WSe $\mathrm{Wh}_{2}$ and $\mathrm{WS}_{2}$ nanoplates. The as-grown $\mathrm{WSe}_{2}$ or $\mathrm{WS}_{2}$ nanoplates on substrates were placed in $10 \mathrm{ml} 30 \% \mathrm{H}_{2} \mathrm{O}_{2}$ solution for the desired time. After the etching reaction, the substrate was picked up and dried with a stream of $\mathrm{N}_{2}$ gas.

Water vapor-assisted etching of screw dislocated $W_{2}$ nanoplates. The as-grown $\mathrm{WS}_{2}$ nanoplates on the substrate were placed in an alumina boat upstream in a fused silica tube inside a Lindberg Blue M tube furnace. An alumina boat filled with $\mathrm{CaSO}_{4} \cdot 2 \mathrm{H}_{2} \mathrm{O}$ powder (approximately $1 \mathrm{~g}$, Sigma 
Aldrich) was placed further upstream from the furnace, where heating tapes controlled the temperature. The tube was heated to $800{ }^{\circ} \mathrm{C}$ under a pressure of 800 torr with an argon flow of 100 sccm. Once the reaction temperature was reached, the $\mathrm{CaSO}_{4} \cdot 2 \mathrm{H}_{2} \mathrm{O}$ was heated to $100{ }^{\circ} \mathrm{C}$ under an argon flow of $100 \mathrm{sccm}$ to release the water vapor, and the $\mathrm{WS}_{2}$ substrate boat was pushed into the furnace by a magnet coupled positioner and a quartz rod to initiate the etching reaction. After desired etching time, the furnace was opened and cooled down rapidly.

Structural Characterizations. The nanoplates were characterized using an optical microscope (Olympus BX51M), a scanning electron microscope (LEO SUPRA 55 VP field-emission SEM) operated at $3 \mathrm{kV}$, and an atomic force microscope (Agilent 5500) with NCHV-A tips (Bruker) in AC-AFM mode.

First-principle calculation of $\mathrm{WSe}_{2}$ edge structures. The Vienna ab initio simulation package was employed to calculate the formation energy and etching kink formation energy of different edges. The Perdew-Burke-Ernzerhof parameterization of generalized gradient approximation (GGA) was used for the exchange-correlation function. The projector-augmented wave potentials were used for ion-electron interactions. The DFT-D2 VDWs density functional was used for the corrections of the interlayer VDWs interaction. The electronic self-consistency criterion was set to $10^{-4} \mathrm{eV}$. For geometry relaxation, the force on atoms was converged below $0.01 \mathrm{eV} \cdot \AA^{-1}$. The formation energy of $\mathrm{W}_{2} / \mathrm{Se}_{0}$ edge was calculated by constructing several triangular $\mathrm{WSe}_{2}$ islands in different sizes with only $\mathrm{W}_{2} / \mathrm{Se}_{0}$ edge. The formation energy differences between $\mathrm{W}_{1} / \mathrm{Se}_{1}$ and $\mathrm{W}_{2} / \mathrm{Se}_{0}$ edges were calculated by comparing formation energy of models in Figure S4c. The models contained six rows of $\mathrm{WSe}_{2}$ zigzag chains and the upper zigzag edge was reconstructed. The period of along the zigzag edge was $9.81 \AA$ with two vacuum layers of $>15 \AA$ along the other 
two directions. The three bottom rows of $\mathrm{WSe}_{2}$ zigzag chains were fixed to mimic $\mathrm{WSe}_{2}$ bulk. Several hexagons were removed in each structure to calculate the kink formation energy of etching. The k-mesh was $3 \times 1 \times 1$ in these calculations. The structures were shown in Figure S4, S5.

Kinetic Monte Carlo simulations of etching screw dislocated WSe 2 nanoplates. The algorithm of kMC was developed in a previous paper. ${ }^{3}$ The events were defined as removing a hexagon from the edge of $\mathrm{WSe}_{2}$ island. The probability of events was defined as $P_{i}=\exp \left(-\frac{E_{(m, n)}\left(r_{i}\right)}{k_{\mathrm{B}} T}\right)$ and could not be larger than 1 , where $k_{\mathrm{B}}$ is the Boltzmann constant, and $T$ is the temperature. The energy was:

$$
E_{(m, n)}(r)=E_{0} \mathrm{eV}-\alpha * m-\beta * n-\Delta \mu\left(k_{\mathrm{Se}}-k_{\mathrm{W}}\right)-\varepsilon \frac{b_{\mathrm{L}}^{2}}{\left(r_{i} / a_{0}\right)^{2}}
$$

where $m$ and $n$ are the numbers of nearest and next-nearest neighbors, $k_{\mathrm{Se} / \mathrm{W}}$ are the numbers of $\mathrm{Se} / \mathrm{W}$ atoms removed in the event, $b_{\mathrm{L}}$ is the number of burger vector in unit of layer distance and $r_{i} / a_{0}$ is the distance from the center in unit of the lattice constant of $\mathrm{WSe}_{2} \cdot E_{0}=16 k_{\mathrm{B}} T$ is a constant, $\alpha=3 k_{\mathrm{B}} T$ and $\beta=1 k_{\mathrm{B}} T$ are the decrease of formation energy of a hexagon caused by the neighbors and $\Delta \mu=2 k_{\mathrm{B}} T$ is the chemical potential difference between $\mathrm{W}$ and Se. $\varepsilon$ is the strain energy of screw dislocation, $\varepsilon=0.5 k_{\mathrm{B}} T$ in the simulations in Fig. 4 and $\varepsilon=2 k_{\mathrm{B}} T$ in the simulations in Fig. S7-S9. Additionally, if there were atoms above the current hexagon, the probability was set to be 0 . The time of each $\mathrm{kMC}$ step was recorded by

$$
t=\tau_{0} \frac{1}{\sum P_{i}^{\prime}}
$$


where the sum is over all events and $\tau_{0}$ is the unit time of molecule vibration $\left(\tau_{0}=\frac{h}{k_{\mathrm{B}} T}\right)$ and $h$ is the Planck constant. The model was put on a platform with screw dislocations,

$$
z(\theta)=z_{0} *\left(l+\frac{\theta}{\pi}\right)
$$

where $z_{0} \approx 6.5 \AA$ is the layer distance, $l$ is the layer and $\theta \in(-\pi, \pi)$ is the angle in $x-y$ plane. A restriction that the atoms in lower layers cannot be etched if the atoms above them still exist was added based on the observation in the experiments. 


\section{Additional Figures:}
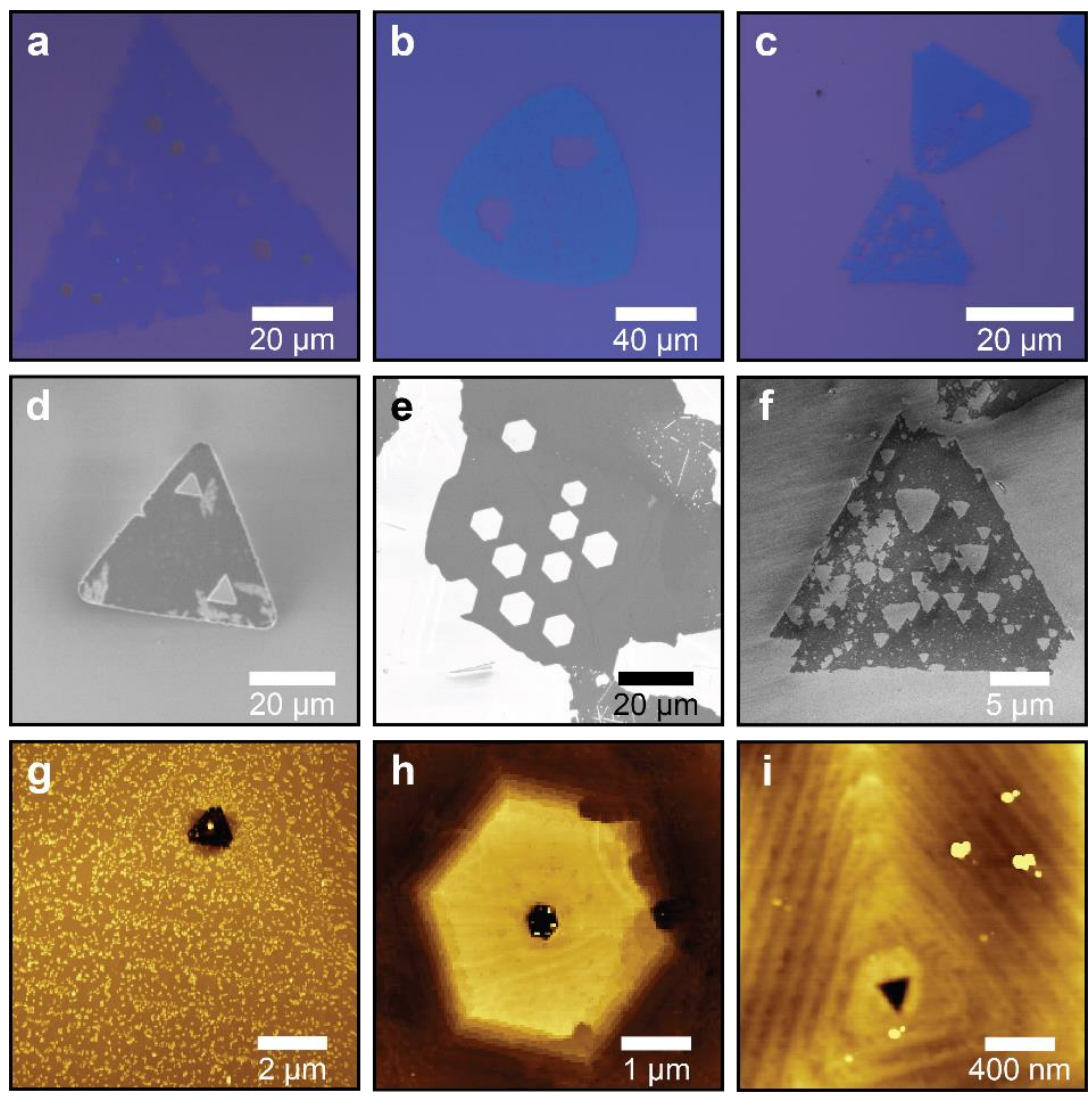

Figure S1. Gas phase water vapor etching of $\mathbf{W S}_{2}$. (a-c) Optical images of $\mathrm{WS}_{2}$ monolayers with (a) parallel triangular holes, (b) hexagonal holes, and (c) inverted triangular holes. (d-f) SEM images of $\mathrm{WS}_{2}$ monolayers with (d) parallel triangular holes, (e) hexagonal holes, and (f) inverted triangular holes. (g-i) AFM images of $\mathrm{WS}_{2}$ spiral plates with (g) parallel triangular holes, (h) hexagonal holes, and (i) inverted triangular holes.

\section{Supplementary Note}

During the reaction, the following reactions as well as their reverse reactions occurred (as explained in other papers $\left.{ }^{2,4}\right)$ :

$$
\mathrm{WS}_{2(\mathrm{~s})}+\mathrm{H}_{2} \mathrm{O}_{(\mathrm{g})} \stackrel{\text { high T }}{\longrightarrow} \mathrm{WO}_{\mathrm{x}}(\mathrm{OH})_{\mathrm{y}_{(\mathrm{g})}}+\mathrm{H}_{2} \mathrm{~S}_{(\mathrm{g})}\left(+\mathrm{H}_{2}(\mathrm{~g})\right)
$$




$$
\mathrm{WO}_{\mathrm{x}(\mathrm{s})}+\mathrm{H}_{2} \mathrm{O}_{(\mathrm{g})} \stackrel{\text { high T }}{\longrightarrow} \mathrm{WO}_{\mathrm{x}}(\mathrm{OH})_{\mathrm{y}_{(\mathrm{g})}}
$$

During the reaction, the edges of a $\mathrm{WS}_{2}$ flake is in equilibrium with the local gas environment around the flake. The local gas environment depends on the position of the $W S_{2}$ flake in the reactor. The gas species generated by the reactions of etching will redistribute by their diffusion and the flow of carrier gas and generally their concentrations are higher along the downstream direction. Although the exact concentration of these gaseous species (such as $\mathrm{WO}_{\mathrm{x}}(\mathrm{OH})_{\mathrm{y}}, \mathrm{H}_{2} \mathrm{~S}, \ldots$ ) is hard to be calculated or measured, we believe both S-rich (with more $\mathrm{H}_{2} \mathrm{~S}$ ) and W-rich (with more $\left.\mathrm{WO}_{\mathrm{x}}(\mathrm{OH})_{\mathrm{y}}\right)$ local environment could be generated in the same reactor. Therefore, due to these reversible reactions and complex dynamics of various reactive species at different locations, both X-rich and M-rich mechanism could happen on the same substrates. 

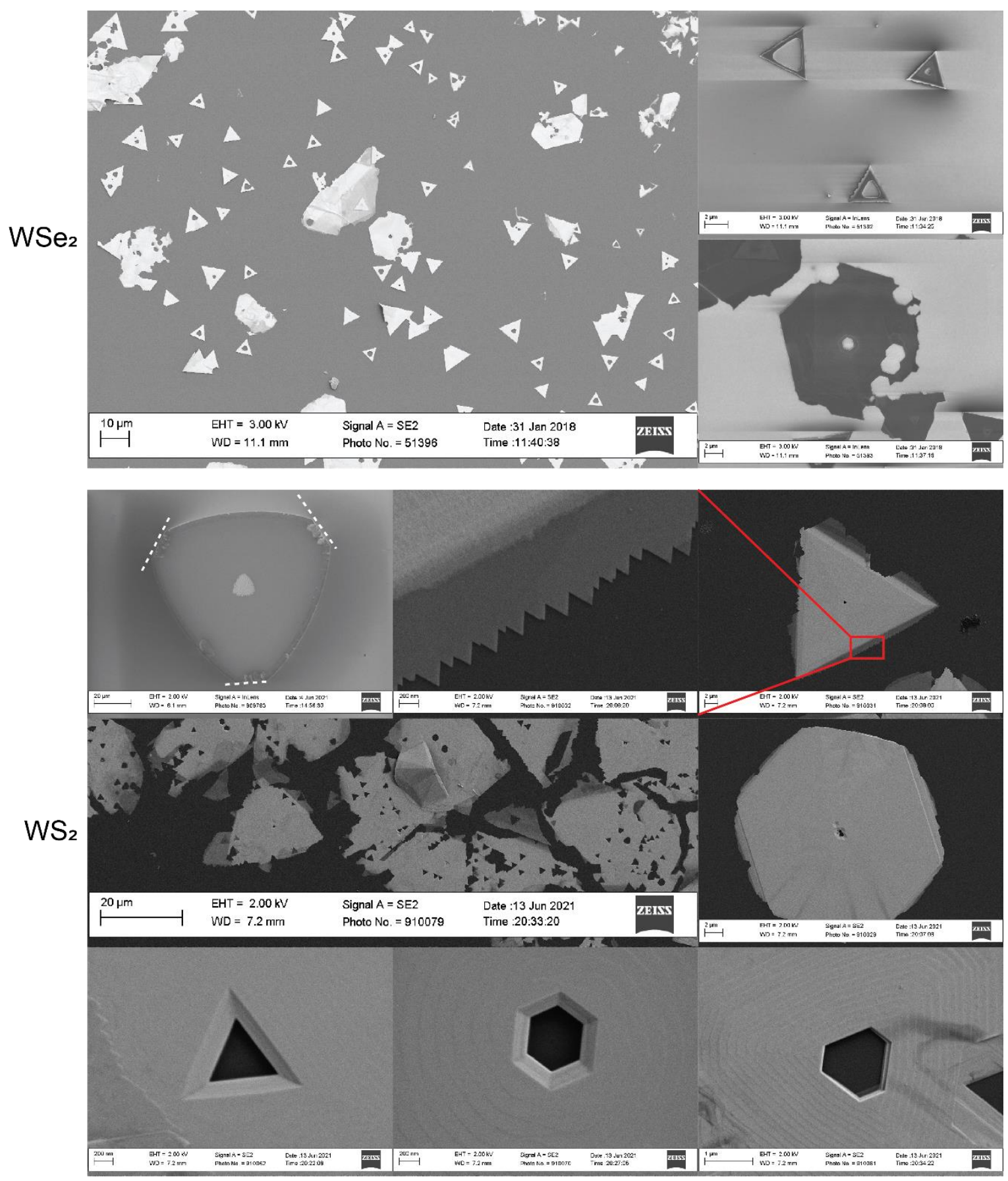

Figure S2. SEM images of WSe2 and $\mathrm{WS}_{2}$ etched by $\mathrm{H}_{2} \mathrm{O}_{2}$.

\section{Supplementary Note}

Why $\mathrm{H}_{2} \mathrm{O}_{2}$ etching follows the M-rich mechanism is related to the kinetics of oxidation in the $\mathrm{H}_{2} \mathrm{O}_{2}$ solution. With excessive $\mathrm{H}_{2} \mathrm{O}_{2}$ etchant, eventually the $\mathrm{M}$ and $\mathrm{X}$ species could be oxidized into their 
high oxidation states via the reaction of:

$$
\mathrm{WS}_{2(\mathrm{~s})}+\mathrm{H}_{2} \mathrm{O}_{2}(\mathrm{aq}) \longrightarrow \mathrm{WO}_{3}\left(\mathrm{H}_{2} \mathrm{O}\right)_{\mathrm{n}(\mathrm{aq})}+\mathrm{H}_{2} \mathrm{SO}_{4(\mathrm{aq})}
$$

This process conceptually can be treated as the disassociation of $\mathrm{MX}_{2}$ in water, and the oxidation of the disassociated species:

$$
\begin{gathered}
\mathrm{WS}_{2(\mathrm{~s})}+(\mathrm{n}+1)_{2} \mathrm{H}_{(\mathrm{l})} \longrightarrow \mathrm{WO}_{2}\left(\mathrm{H}_{2} \mathrm{O}\right)_{\mathrm{n}(\mathrm{aq})}+\mathrm{H}_{2} \mathrm{~S}_{(\mathrm{aq})} \\
\mathrm{WO}_{2}\left(\mathrm{H}_{2} \mathrm{O}\right)_{\mathrm{n}(\mathrm{aq})}+\mathrm{H}_{2} \mathrm{O}_{2}(\mathrm{aq}) \\
\mathrm{H}_{2} \mathrm{~S}_{(\mathrm{aq})}+4 \mathrm{HO}_{2}\left(\mathrm{H}_{2} \mathrm{O}\right)_{\mathrm{m}(\mathrm{aq})}+(\mathrm{n}-\mathrm{m}+1) \mathrm{H}_{2} \mathrm{O}_{(\mathrm{l})} \\
\longrightarrow \mathrm{H}_{2} \mathrm{SO}_{4(\mathrm{aq})}+4 \mathrm{H}_{2} \mathrm{O}_{(\mathrm{l})}
\end{gathered}
$$

The etching reaction is directly related to the instantaneous concentration of $\mathrm{WO}_{2}\left(\mathrm{H}_{2} \mathrm{O}\right)_{\mathrm{n}}$ and $\mathrm{H}_{2} \mathrm{~S}$ in the solution. If the oxidation rate of $\mathrm{H}_{2} \mathrm{~S}$ is much higher than the oxidation rate of $\mathrm{WO}_{2}\left(\mathrm{H}_{2} \mathrm{O}\right)_{\mathrm{n}}$, the reaction can be shifted to the M-rich direction.

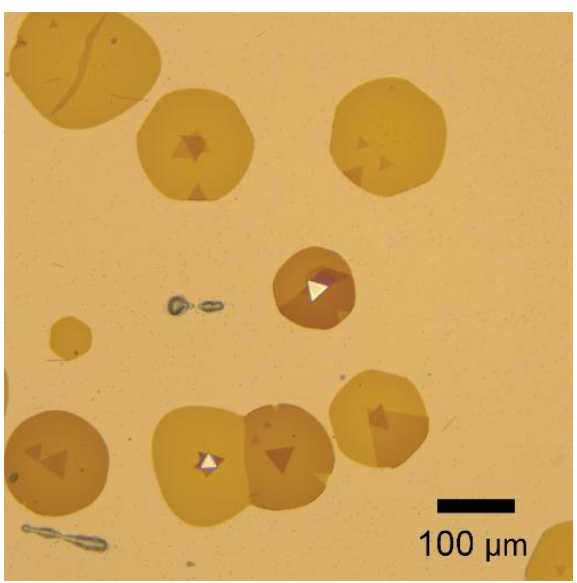

Figure S3. WS 2 grown by water vapor-assisted chemical vapor transport on a silicon wafer that show the rounded corners caused by the etching process. 
(a)

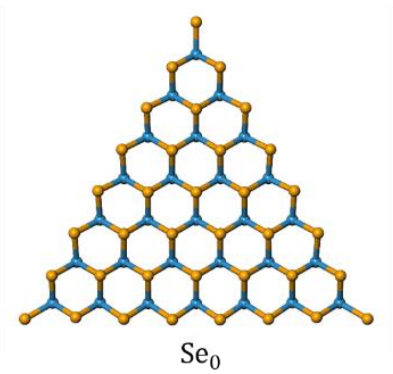

(b)

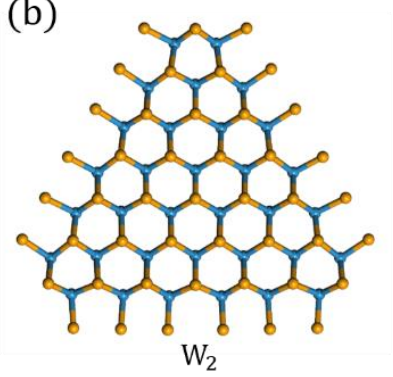

(c)
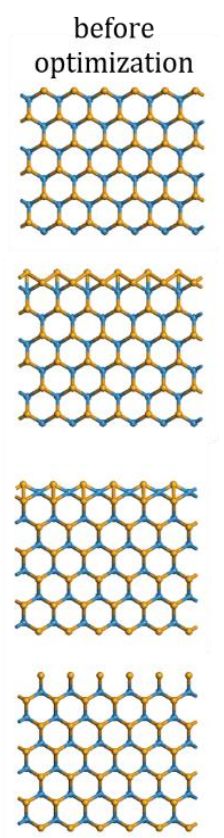
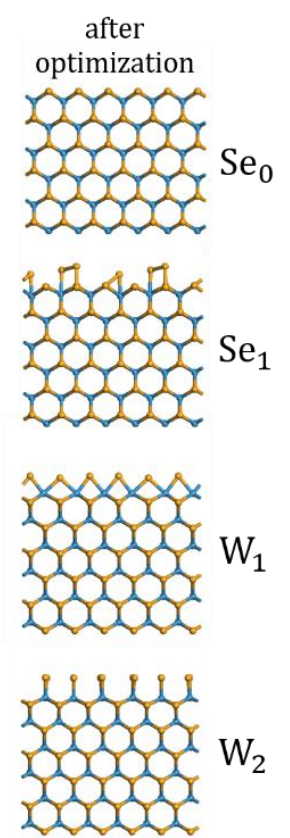

Figure S4. Illustration of the WSe2 edge structures with different numbers of selenium atom terminations.
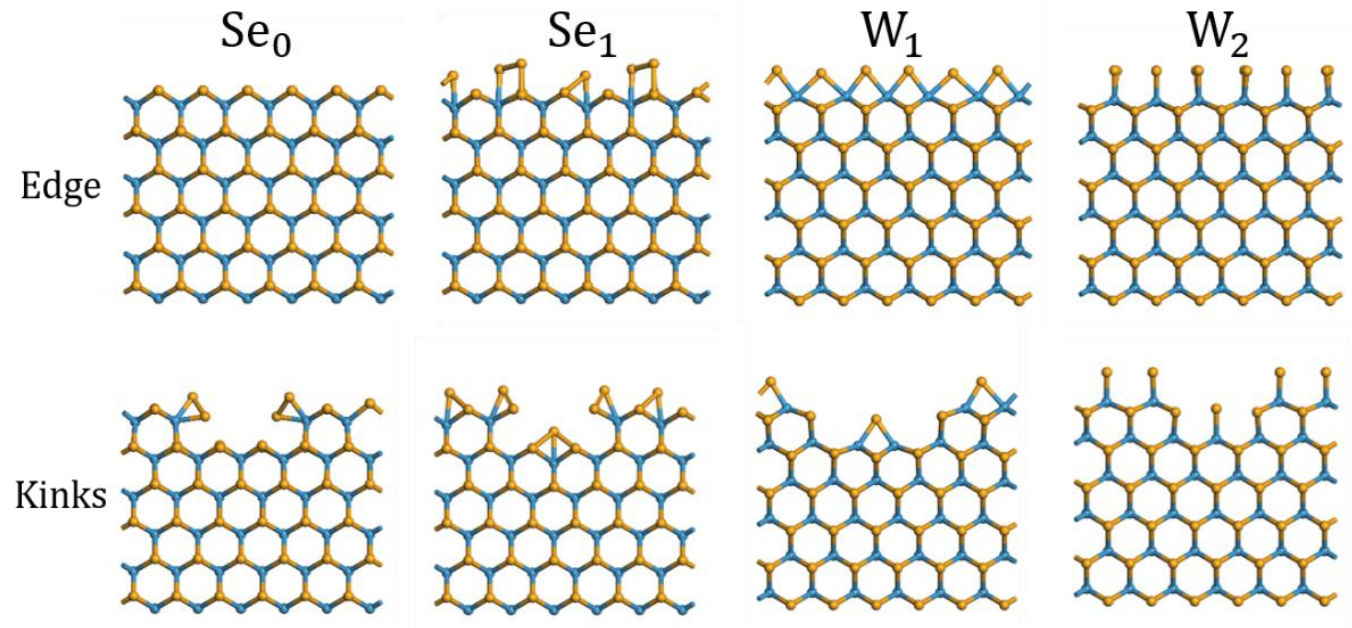

Figure S5. Illustration of the WSe2 edge etching kink structures with different numbers of selenium atom terminations. 


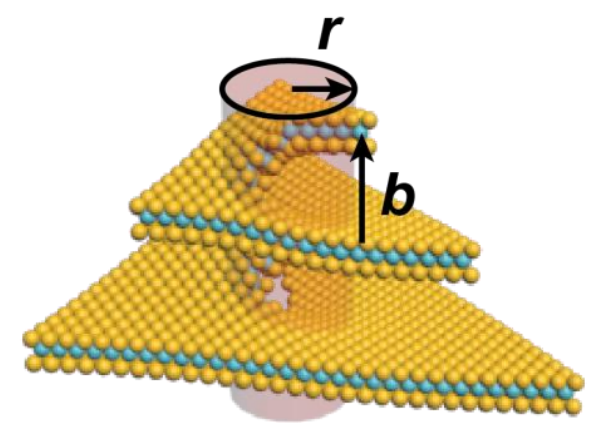

Figure S6. The burgers vector of a screw dislocation.

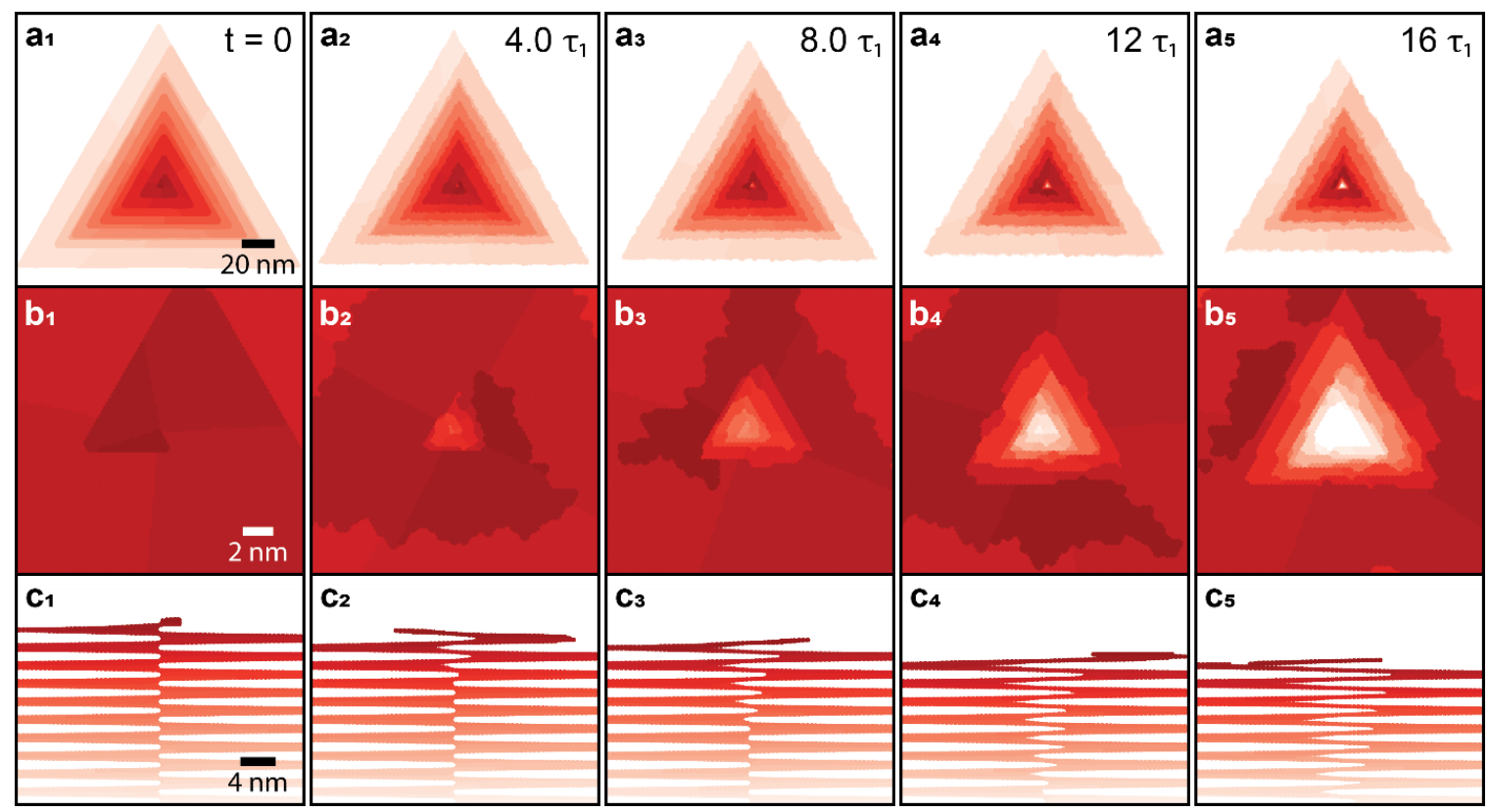

Figure S7. The morphology evolutions of the top (a and b) and cross-sectional (c) views of a 1-layer triangular WSe 2 spiral with [+] stacking. See animation in Supporting Video 1. 


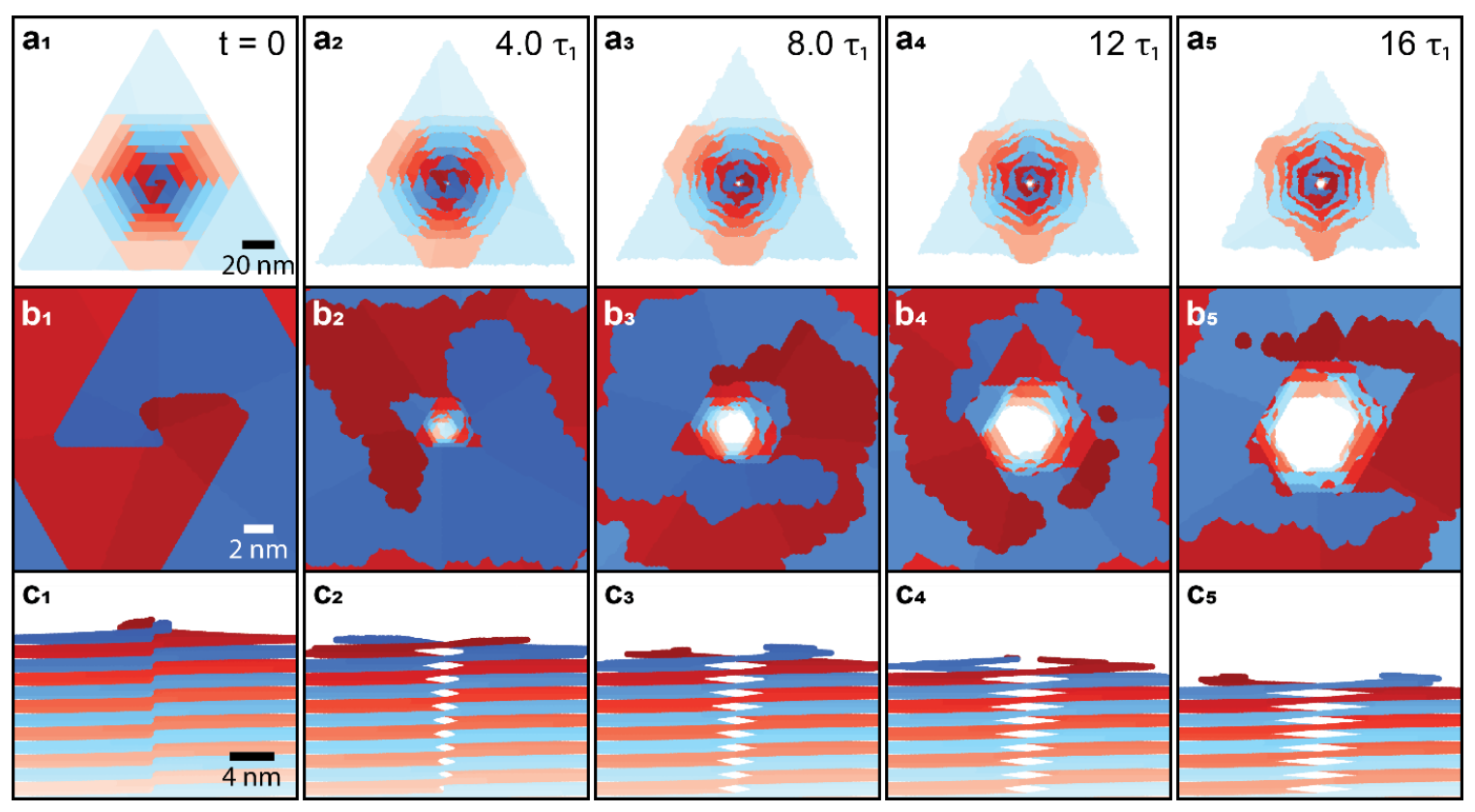

Figure S8. The morphology evolutions of the top (a and b) and cross-sectional (c) views of a 2-layer hexagonal WSe2 spiral with [+-] stacking. See animation in Supporting Video 2.

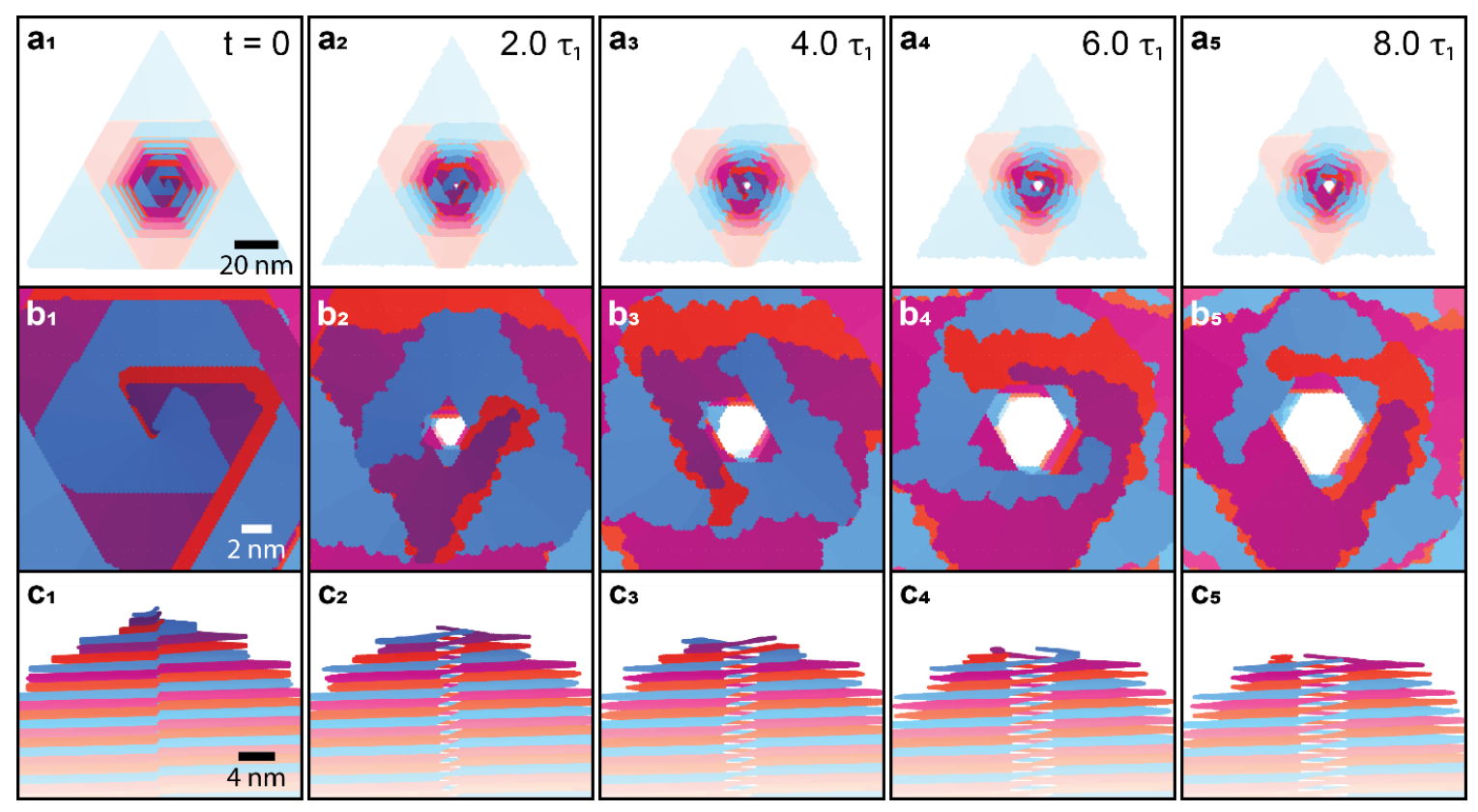

Figure S9. The morphology evolutions of the top (a and b) and cross-sectional (c) views of a 3-layer truncated triangular WSe2 spiral with $[++-]$ stacking. See animation in Supporting Video 3. 


\section{References cited in the Supporting Information}

(1) Shearer, M. J.; Samad, L.; Zhang, Y.; Zhao, Y.; Puretzky, A.; Eliceiri, K. W.; Wright, J. C.; Hamers, R. J.; Jin, S. Complex and Noncentrosymmetric Stacking of Layered Metal Dichalcogenide Materials Created by Screw Dislocations J. Am. Chem. Soc. 2017, 139, 3496-3504. (2) Zhao, Y.; Jin, S. Controllable Water Vapor Assisted Chemical Vapor Transport Synthesis of $\mathrm{WS}_{2}-\mathrm{MoS}_{2}$ Heterostructure ACS Materials Lett. 2020, 2, 42-48.

(3) Kong, X.; Zhuang, J.; Zhu, L.; Ding, F. The Complementary Graphene Growth and Etching Revealed by Large-Scale Kinetic Monte Carlo Simulation Npj Comput. Mater. 2021, 7, 14.

(4) Sahoo, P. K.; Memaran, S.; Xin, Y.; Balicas, L.; Gutiérrez, H. R. One-Pot Growth of TwoDimensional Lateral Heterostructures via Sequential Edge-Epitaxy Nature 2018, 553, 63-67. 